\title{
Flexible Outsourcing, Profit Sharing and Equilibrium Unemployment
}

\author{
Erkki Koskela \\ University of Helsinki, RUESG and HECER \\ and \\ Jan König \\ Freie Universität Berlin
}

Discussion Paper No. 230

August 2008

ISSN 1795-0562

HECER - Helsinki Center of Economic Research, P.O.Box 17 (Arkadiankatu 7), FI-00014 University of Helsinki, FINLAND, Tel +358-9-191-28780, Fax +358-9-191-28781, E-mail info-hecer@helsinki.fi, Internet www.hecer.fi 


\title{
Flexible Outsourcing, Profit Sharing and Equilibrium Unemployment*
}

\begin{abstract}
We analyze the questions associated with flexible outsourcing with both committed and flexible profit sharing under imperfect domestic labour markets. How does profit sharing affect flexible outsourcing? What is the relationship between outsourcing cost, profit sharing and equilibrium unemployment, when profit sharing is also a part of the compensation schemes on other industries? In the case of committed profit sharing outsourcing cost increases wage. Optimal flexible profit sharing is smaller than in the absence of outsourcing, but outsourcing cost and wage will have ambiguous on optimal flexible profit sharing. Implementing profit sharing can help to avoid outsourcing due to a direct productivity effect and a wage effect. For equilibrium unemployment the effects of outsourcing cost and profit sharing are ambiguous both in the case of committed and flexible profit sharing. In the case of zero effort elasticity there is no committed or flexible profit sharing in the absence or presence of outsourcing and in this case lower outsourcing cost will decrease unemployment.
\end{abstract}

JEL Classification: E23, E24, H22, J23, J33, J82.

Keywords: Flexible outsourcing, profit sharing, labour market imperfection, employee effort, equilibrium unemployment.

\section{Erkki Koskela}

Department of Economics

University of Helsinki

P.O.Box 17 (Arkadiankatu 7)

FI-00014 University of Helsinki

FINLAND

e-mail: erkki.koskela@helsinki.fi
Jan König

School of Business \& Economics

Freie Universität Berlin

Boltzmannstr. 20

DE-14915 Berlin

GERMANY

e-mail: jan.koenig@fu-berlin.de

\footnotetext{
* The authors thank the Research Unit of Economic Structures and Growth (RUESG) financed by Academy of Finland, University of Helsinki, Yrjö Jahnsson Foundation, Bank of Finland and Nokia Group, for financial support. Koskela also thanks Academy of Finland (grant No.1117698) for further financial support and Freie Universität Berlin for great hospitality and König thanks RUESG for great hospitality.
} 


\section{Introduction}

Wage differences constitute a central explanation for the increasing business practice of international outsourcing across industries (see e.g. Sinn (2007) or Stefanova (2006) concerning the East-West dichotomy of outsourcing). It is important to mention that Amiti and Wei (2005) and Rishi and Saxena (2004) emphasize the big difference in labour costs as the main explanation for the strong increase in outsourcing of both manufacturing and services to countries with low labour costs. Of course one reason for these wage gaps is the difference of labour market institutions. In most western European countries the wage is still determined by bargaining between firms and trade unions, but e.g. in eastern European or Asian countries there is either no wage bargaining or trade unions are much weaker.

Concerning the analysis of the effect of outsourcing on compensation schemes under wage bargaining there are two focuses in the literature, the case of committed outsourcing and flexible outsourcing. While in the committed case, outsourcing takes place before wage bargaining ${ }^{1}$, but in the flexible case outsourcing is decided after wage bargaining. Our focus in this paper is to assume that outsourcing is flexible, i.e. determined simultaneously with domestic labour demand, but after wage formation. Skaksen (2004) has analyzed flexible outsourcing using a CobbDouglas production function by assuming that output good is produced by combining two intermediate activities, where one activity can be perfect substitute by outsourcing. Also Braun and Scheffel (2007) have developed a simple two-stage game between a monopoly union and a firm by assuming that the labour union sets wages before firms decide on the degree of outsourcing. But in these papers they have abstracted from the analysis of profit sharing as a part of the compensation scheme, which is our focus. ${ }^{2}$

Since in the case of flexible outsourcing wage bargaining has taken before outsourcing decision, the opportunity of external procurement can be use as a threat in

$1 \quad$ See e.g. Perry (1997) for an overview about the relationship between outsourcing and wage bargaining. Also e.g. Danthine and Hunt (12994), Zhao (2001) and Koskela and Stenbacka (2007) have analyzed committed outsourcing issue.

2 There are also some new analysis, which incorporated flexible outsourcing and wage bargaining, e.g. Koskela and Poutvaara (2008) or Koskela (2008). But the mainly focus in these papers are labour taxation issues in the absence of profit sharing. 
the bargaining round and lowers the wage. If domestic labour and outsourcing are perfect substitutes, domestic wages have to be lower than outsourcing cost, so the price for external procurement is an upper bound. It is intuitively that to keep domestic production attractive, it needs lower marginal costs or wages. If lower costs are not possible, then firms have to increase productivity of domestic production, which is influenced by workers' effort. One way to try to stimulate effort is profit sharing, which may reduce wages because part of the former base wage can be substituted by profit income. Empirical studies show that profit sharing is an important phenomenon in many OECD countries. Pendleton et al (2001) have presented delailed data on profit sharing schemes in 14 OECD countries. ${ }^{3}$ As profit sharing is now commonly incorporated in the compensation schemes and international outsourcing has recently increased e.g. in western EU-countries and in the United States, it is important to study the implications of both outsourcing and profit sharing for wage bargaining and equilibrium unemployment. ${ }^{4}$

We extend the literature of flexible outsourcing by implementing profit sharing as a part to the compensation scheme. In our analysis we distinguish two different time sequences of profit sharing, i.e. by assuming that profit sharing might be committed or flexible in terms of wage formation. The idea behind the implementation of profit sharing is that this will induce incentives to increase effort and so productivity for given wage level. Profit sharing will also affect the wage formation, what could lead to a lower base wage since a part of the former wage level is substitute by profit income.

In this paper we analyze the following questions associated with flexible outsourcing both with committed and flexible profit sharing under imperfect domestic labour markets. First, how does outsourcing cost influence both wage formation and profit sharing? Second, how does profit sharing influence flexible outsourcing? Third, what is the relationship between flexible outsourcing, profit sharing and equilibrium unemployment, when profit sharing is also a part of the compensation schemes in other industries?

See also Conyon and Freeman (2001).

In the presence of committed outsourcing sharing, which is decided before wage formation, Koskela and König (2008) have analyzed the relationship between profit sharing, exogenous outsourcing and equilibrium unemployment. 
We find that in both profit sharing scenarios lower outsourcing cost lowers the wage. In the presence of flexile outsourcing profit sharing is a supplementary or compensating part of income. If there is no outsourcing, profit sharing has also an ambiguous character. In the presence of flexible outsourcing optimal flexible profit sharing is smaller than in the absence of outsourcing. Moreover, lower outsourcing cost and higher wage will have ambiguous effect on optimal flexible profit sharing and also on optimal committed profit sharing.

In the case of zero effort elasticity there is of course no committed or flexible profit sharing in the absence or presence of outsourcing. In these cases the wages are the same both in the presence and absence of outsourcing. Under positive effort elasticity without outsourcing higher profit sharing will lead to a smaller wage compared to the flexible case and vice versa.

In terms of equilibrium unemployment the effects of outsourcing cost and profit sharing are ambiguous both in the committed and flexible profit sharing. In the absence of outsourcing profit sharing will also have an ambiguous unemployment effect. Moreover, if effort elasticity is zero, higher outsourcing cost will enhance the unemployment.

We proceed as follows. Section 2 presents the basic structure of theoretical framework in the presence of flexible outsourcing and two different time sequences in terms of profit sharing decision. The determination of labour demand, outsourcing and employee effort are presented in Section 3. Section 4 investigates the wage formation by monopoly labour union with committed profit sharing and in section 5 with flexible outsourcing and flexible profit sharing. Section 6 explores the implications of flexible outsourcing and different time decisions of profit sharing on equilibrium unemployment. Finally, we present conclusions in section 7.

\section{The Basic Framework}

We assume that output depends not only on domestic labour and international outsourcing, but also on the effort by workers, i.e. the workers' productivity. This lies in conformity with the efficiency wage hypothesis (see e.g. the book edited by 
Akerlof and Yellen (1986)). We analyze two alternative timing decisions. The timing structure (I) captures the idea that the representative firm is flexible to decide about the amount of outsourcing simultaneously with domestic labour demand, but commits to profit sharing in anticipation of wage determination. After the firm has decided about profit sharing, the monopoly trade union set the wage with respect to the profit share level. Knowing the base wage the representative firm determines outsourcing and employment. If the wage and profit share level is known, the representative worker decides on effort provision. The partly alternative timing structure (II) will change the timing of determination of profit sharing and wage determination so that the representative firm decides profit sharing after wage formation. If both compensation parts are known the firm will be flexible to decide on outsourcing and labour demand. Also the worker will decide about his effort after knowing the earnings components. We summarize these alternative timing decisions in Figure 1.

Figure 1: Alternative time sequences of decisions in terms of outsourcing, employment, effort, wage formation and profit sharing

(I) Flexible outsourcing and committed profit sharing:

\begin{tabular}{lll} 
Stage 1 & Stage 2 & Stage 3 \\
\hline profit & wage & outsourcing $M$, labour demand $L$ \\
sharing $\tau$ & formation $w$ & and effort determination $e$
\end{tabular}

(II) Flexible outsourcing and flexible profit sharing:

\begin{tabular}{lll} 
Stage 1 & Stage 2 & Stage 3 \\
\hline $\begin{array}{ll}\text { wage } \\
\text { formation } w\end{array}$ & $\begin{array}{l}\text { profit } \\
\text { sharing } \tau\end{array}$ & $\begin{array}{l}\text { outsourcing } M, \text { labour demand } L \\
\text { and effort determination } e\end{array}$
\end{tabular}

In the following sections we analyze these two alternative time sequences of decisions both in the case of committed profit sharing and flexible profit sharing in terms of the relationship to the wage formation of the monopoly labour union. 


\section{Optimal Outsourcing, Labour Demand and Employee Effort}

In this section we characterize the optimal labour demand and outsourcing by the representative firm and the effort by the representative worker by taking profit sharing, $\tau$, and wage, $w$, as given. The revenue function is presented as

$$
R(L, M)=\frac{\delta}{\delta-1}(e L+M)^{\frac{\delta-1}{\delta}}, \quad \delta>1
$$

where $L$ is the amount of domestic labour and $M$ the firm's labour input acquired from external suppliers through outsourcing. Here we assume that there is a perfect substitutability between domestic labour and outsourcing. ${ }^{5}$

The firm decides on domestic labour and outsourcing so as to maximize the profit function

$$
\underbrace{\operatorname{Max}}_{L, M} \pi=\frac{\delta}{\delta-1}(e L+M)^{\frac{\delta-1}{\delta}}-w L-\frac{1}{2} c M^{2} .
$$

by taking worker's effort, the negotiated wage and profit sharing as given. We assume that there is a convex cost of establishing capacity for foreign outsourced activity. The first-order conditions are $\pi_{L}=e \cdot(e L+M)^{-\frac{1}{\delta}}-w=0$ and $\pi_{M}=(e L+M)^{-\frac{1}{\delta}}-c M=0$ and these can be expressed as

$$
\begin{aligned}
& L=w^{-\delta} e^{\delta-1}-\frac{M}{e}=w^{-\delta} e^{\delta-1}-\frac{w}{c e^{2}}, \\
& M=\frac{w}{c e} .
\end{aligned}
$$

Concerning $\delta>1$ specifying the inverse product function according to a monopolistic product market competition (for details, see the seminal paper by Dixit and Stiglitz (1977)) as $p=\frac{\delta}{\delta-1} D^{-\frac{1}{\delta}}, \delta>1$ gives the inverse elasticity of demand $-p_{D} D / p=1 / \delta$ so that $-D_{p} p / D=\delta$. Assuming $F=e L+M$ and $F=D$ gives another suggestion for (1). 
Domestic labour demand is a negative function of wage and the amount of outsourcing and a positive function of both outsourcing cost and effort. Higher outsourcing will decrease domestic labour demand, which lies in conformity with empirics (see e.g. Senses (2006)). However, labour demand does not directly depend on profit sharing, which lies also in conformity with empirical evidence. ${ }^{6}$ For outsourcing we found that the external procurement is a positive function of wage rate and a negative function of both outsourcing cost and effort. The reactions could be described by the outsourcing elasticities in terms of outsourcing cost, effort and wage as follows: $\frac{M_{c} c}{M}=\frac{M_{e} e}{M}=-1$ and $\frac{M_{w} w}{M}=(1-\gamma)>0$ so that these are constant.

The effort provision of the worker is associated with a disutility, which is assumed to satisfy the following convex function $g(e)=\gamma e^{1 / \gamma}$ with $0<\gamma<1$, i.e. $g^{\prime}(e), g^{\prime \prime}(e)>0$. The individual utility function for the employed worker is (4a) and for the unemployed worker (4b)

$$
\begin{aligned}
& v=w+\frac{\tau}{L} \pi-g(e), \\
& \bar{v}=b,
\end{aligned}
$$

where $\pi$ captures the firm's profit and $b$ stands for the unemployed worker's exogenous outside option.

Utility maximization yields the optimal effort level. The first-order condition in terms of effort determination for (4a) is

$$
v_{e}=\frac{\tau}{L} \pi_{e}-g^{\prime}(e)=0 .
$$

Using $g^{\prime}(e)=e^{(1 / \gamma)-1}$ and $\pi_{e}=(e L+M)^{-\frac{1}{\delta}} L$ equation (5) implies

$$
e=(\tau w)^{\gamma}
$$

\footnotetext{
$6 \quad$ See e.g. Wadwani and Wall (1990) and Cahuc and Dormont (1997).
} 
where $\gamma=\frac{e_{\tau} \tau}{e}=\frac{e_{w} w}{e}$ is the elasticity of effort with respect to profit sharing and wage rate (see about this, Koskela and Stenbacka (2006)). Therefore the optimal effort by worker is $e_{w}=\frac{\gamma e}{w}$ and $e_{\tau}=\frac{\gamma e}{\tau}$, so that profit sharing and base wage enhance productivity by increasing effort provision and affect positively labour demand indirectly. ${ }^{7}$ But outsourcing will have no effect in the case of perfect substitutability between outsourcing and effective domestic labour.

The wage elasticity of labour demand, which turns out to be important later on, can be expressed as

$$
\eta \equiv-\frac{L_{w} w}{L}=(1-\gamma)\left[\delta+(1+\delta) \frac{M}{e L}\right]+\gamma=\eta^{c}+(1-\gamma) \frac{M}{e L}
$$

where $\eta^{c}=(1-\gamma) \delta\left(1+\frac{M}{e L}\right)+\gamma$ is the wage elasticity of labour demand under committed outsourcing. In both scenarios the wage elasticity depends on parameters $\delta$ and $\gamma$ and also on outsourcing and wage rate via $L$ and $e$.

\section{Wage Formation by Monopoly Labour Union with Flexible Outsourcing and Committed Profit Sharing}

Now we analyze the timing structure (I) when the representative firm commits to profit sharing before the wage formation by allowing for their effects on labour demand and effort determination.

This finding lies in conformity with empirics (see e.g. Booth and Frank (1999), Cable and Wilson (1990), Cahuc and Dormont (1997), Kruse (1992), and Wadhwani and Wall (1990)). Of course, we have to mention that these issues have not been studied to our knowledge empirically in the presence of outsourcing. Also in the theoretical focus of the literature we find evidence of increasing effort by higher wages, see e.g. Lin et al. (2002). 


\subsection{Wage Formation under Committed Profit Sharing}

By analyzing the wage formation under committed profit sharing the objective function of monopoly labour union is assumed to be $V=v L+(N-L) \bar{v}$, which we can rewrite by using equations (4a) and (4b) as

$$
V=(w-b) L+\tau \pi-g(e) L+b N,
$$

where $b$ captures the exogenous minimum income for labour union members $N$. Maximizing in terms of the base wage subject to labour demand, effort determination, and profit sharing, gives

$$
V_{w}=L+L_{w}(w-b)+\tau \pi_{w}-g(e) L_{w}-L g^{\prime}(e) e_{w}=0,
$$

which can be solved as $w[\eta(1-\gamma \tau)-(1-\tau)]=\eta b$, so that we have

$$
w=\left[\frac{\eta}{\eta(1-\gamma \tau)+\tau-1}\right] b .
$$

This is an implicit form concerning wage formation because both the nominator and denominator of the mark-up depend in a non-linear way on the wage rate. First we have to show the relationship between wage elasticity of labour demand and base wage, profit sharing and outsourcing cost.

The dependence of the wage elasticity of labour demand on base wage is characterized by $\eta_{w}=(1-\gamma)(1+\delta)\left[\frac{e L M_{w}-M\left(e_{w} L+L_{w} e\right)}{(e L)^{2}}\right]$ so that we have a positive relation between elasticity and base wage, i.e.

$$
\eta_{w}=\frac{1}{w}\left((1-\gamma)(1+\delta) \frac{M}{e L}\right)\left((1-\gamma)(1+\delta)\left(1+\frac{M}{e L}\right)\right)>0
$$


by using $1-\gamma+\eta-\gamma=(1-\gamma)(1+\delta)\left(1+\frac{M}{e L}\right)>0$. In the absence of outsourcing we have $\left.\eta_{w}\right|_{M=0}=0$ so wage does not affect the wage elasticity of labour demand and the wage elasticity in this case is smaller, i.e. $\left.\eta\right|_{M=0}=\bar{\eta}=(1-\gamma) \delta+\gamma<\eta$. In this case the wage elasticity is constant and the base wage can be expressed as

$$
\left.w\right|_{M=0}=\bar{w}=\left[\frac{\bar{\eta}}{\bar{\eta}(1-\gamma \tau)+\tau-1}\right] b
$$

which is an explicit specification.

The reaction of the wage elasticity subject to profit sharing in the presence of outsourcing is $\eta_{\tau}=(1-\gamma)(1+\delta)\left[\frac{e L M_{\tau}-M\left(e_{\tau} L+L_{\tau} e\right)}{(e L)^{2}}\right]$ so that it can be written as

$$
\eta_{\tau}=-(1-\gamma)(1+\delta)^{2} \frac{M}{e L} \frac{\gamma}{\tau}\left(1+\frac{M}{e L}\right)<0
$$

Higher profit sharing will increase effort and so effective labour, so that the wage elasticity of labour demand is more inelastic. In the absence of outsourcing, profit sharing does not affect the wage elasticity of labour demand, i.e. $\left.\eta_{\tau}\right|_{M=0}=0$. The reaction of the wage elasticity subject to outsourcing cost is described by $\eta_{c}=(1-\gamma)(1+\delta)\left[\frac{e L M_{c}-M e L_{c}}{(e L)^{2}}\right]=(1-\gamma)(1+\delta) \frac{M}{c e L}\left[\frac{M_{c} c}{M}-\frac{L_{c} c}{L}\right]$ so that it is
$\eta_{c}=-(1-\gamma)(1+\delta) \frac{M}{c e L}\left(1+\frac{M}{e L}\right)<0$.

Higher outsourcing cost will decrease the wage elasticity of labor demand and will reduce ceteris paribus the demand of outsourcing, which leads to a decrease of the ratio of outsourcing and effective labour, which makes the labour damnd more inelastic. This lies in conformity with empirics (see e.g. Hasan et al. ((2007), Slaughter (2001) and Senses (2006)). 
We can look at the wage reaction concerning changes in profit sharing and outsourcing cost by taking the total differentiation of equation (10). For the effect of profit sharing on the base wage by using $b=\frac{w[\eta(1-\gamma \tau)+\tau-1]}{\eta}$, we found (see Appendix A)

$$
\frac{d w}{d \tau}=\frac{(\tau-1) \eta_{\tau} w / \eta-w(1-\eta \gamma)}{\eta(1-\gamma \tau)+(\tau-1)\left(1-\eta_{w} w / \eta\right)}=?
$$

where $(\tau-1)\left(1-\eta_{w} w / \eta\right)>0 .{ }^{8}$ In the absence of outsourcing we have

$$
\left.\frac{d w}{d \tau}\right|_{M=0}=\bar{w}_{\tau}=\frac{-w(1-\bar{\eta} \gamma)}{\bar{\eta}(1-\gamma \tau)+\tau-1}=?
$$

so that profit sharing could have both in the presence and absence of outsourcing an supplementary or complementary character. ${ }^{9}$ This results since profit sharing has opposed effects on the mark-up. In the presence of outsourcing, higher profit sharing will decrease wage elasticity so that a higher wage will have a smaller value loss of the trade union via less dismissal and it is beneficial for the union to set a higher wage. This describes the indirect effect. The direct effect of profit sharing on the base wage, we can see in the denominator of (10) and (10'). Here we can distinguish two working channels. The first part of the denominator describes the productivity channel, since it depends on the effort elasticity $\gamma$. Higher profit sharing will enhance the productivity effect and will lead to an increasing base wage. In the second part of the denominator we have the substitution effect. This effect will decrease the base wage, which means that a former part of the base wage is substituted by profit income. So in our analysis we have the interplay of the positive indirect effect via wage elasticity and the ambiguous direct effect via a positive productivity effect and a

This result is available upon request.

There is also some empirical evidence for both properties. Black and Lynch (2000) show by using U.S. data, that profit sharing results in lower regular pay for workers, what implies a compensatory character, but in Wadhwani and Wall (1990) by using UK data and also in Kraft and Ugarkovic (2005) by using German panel data it has been shown that introducing profit sharing do not reduce the wage, what implies a supplementary character. 
negative substitution effect. In the case of no outsourcing we know that the wage elasticity is constant, so that in this case implementing profit sharing will induce only the ambiguous direct effect.

For the special case of zero effort elasticity, $\gamma=0$, in the presence of outsourcing in our model we observe for the direct working channel only the substitution effect, since a single worker has no effect on the firm profit he will provide in any case a constant effort level of one. Also in this scenario we have an ambiguous effect of implementing profit sharing, since the substitution effect will lower the wage, while the indirect effect will increase the wage. But for the special case of zero effort elasticity in the absence of outsourcing there is negative effect of implementing profit sharing, i.e. $\left.\frac{d w}{d \tau}\right|_{\gamma=0=M}=\frac{-w}{\delta-1}<0$.

In the case of outsourcing cost we get

$$
\frac{d w}{d c}=\frac{(\tau-1) \eta_{c} w / \eta}{\left(\eta(1-\gamma \tau)+(\tau-1)\left(1-\eta_{w} w / \eta\right)\right)}>0
$$

so that lower outsourcing cost in the presence of flexible outsourcing will lower the wage. This holds, since lower outsourcing cost means for given wage level higher outsourcing demand, so that the labour demand elasticity becomes more elastic. As a result of this the wage has to fall, since the trade union can avoid higher outsourcing with lower in-house cost and make integrated production more attractive. ${ }^{10}$

We can summarize our findings to

Proposition 1: In the presence of flexible outsourcing profit sharing is a supplementary or compensating part of income and lower outsourcing cost will lower the wage. If there is no outsourcing, profit sharing has also an ambiguous character on the base wage.

Now we analyze the effect of implementing profit sharing in a firm which engages in outsourcing. From the former results we can rewrite the working channel of

10 This lies in conformity with empirics according to which there is substitutability between outsourcing and domestic labour (see e.g. Munch and Skaksen (2005)). 
committed profit sharing on the amount of outsourcing as $\frac{d M}{d \tau}=\frac{\partial M}{\partial e} \cdot \frac{d e}{d \tau}+\frac{\partial M}{\partial w} \cdot \frac{d w}{d \tau}$ with $\frac{d e}{d \tau}=\frac{\partial e}{\partial \tau}+\frac{\partial e}{\partial w} \cdot \frac{d w}{d \tau}$. Inserting the different expression and simplifying yields

$$
\frac{d M}{d \tau}=\frac{1-\gamma}{c e} \frac{d w}{d \tau}-\frac{\gamma}{\tau} \cdot M=?
$$

The effect of implementing profit sharing is ambiguous since the effect on the base wage is ambiguous. For the case of a complementary character we know that $\frac{d w}{d \tau}<0$. In this scenario implementing profit sharing will reduce the demand for outsourcing. This relationship is intuitively for the following reason. Higher profit sharing will increase effort, since workers participate on the firms profit and have an incentive to increase the profit by higher effort. When higher effort leads to an increasing labour demand some outsourcing activities will be avoided. But higher profit sharing will also affect the base wage. If profit sharing has a complementary character, higher profit sharing leads to a lower base wage. Since only the base wage enters the marginal cost, the advantage of integrated production increases by inducing a higher labour demand. In what follows the amount of outsourcing will be lower with higher profit sharing. In this case profit sharing has to working channels. The first is the stimulating productivity effect by higher effort and the second is the wage reduction effect by substituting wage income by profit income. Both channels are working in the same directions and lead to lower outsourcing demand so that we have

Proposition 2: If profit sharing has a compensatory character, implementing committed profit sharing will stimulating productivity and decrease the marginal cost, so that in this case outsourcing activities are decreasing.

\subsection{Committed Profit Sharing}


Concerning the timing structure (I) the representative firm commits to profit sharing to maximize profit subject to labour demand (3a), outsourcing (3b), effort determination (6) and wage formation (10) so that

$$
\begin{aligned}
\operatorname{Max}_{\tau} \bar{\pi} & =(1-\tau)\left[\frac{\delta}{\delta-1}(e L+M)^{\frac{\delta-1}{\delta}}-w L-\frac{1}{2} c M^{2}\right] \\
L & =w^{-\delta} e^{\delta-1}-\frac{M}{e}=w^{-\delta} e^{\delta-1}-\frac{w}{c e^{2}} \\
e & =(\tau w)^{\gamma} \\
w & =\frac{\eta}{\eta\left(1-\gamma \tau^{c}\right)-\left(1-\tau^{c}\right)} b
\end{aligned}
$$

The first-order condition is $-\pi+(1-\tau) \pi_{\tau}=0$, where the indirect profit can be written as $\pi=\frac{1}{\delta-1}\left[w^{1-\delta} e^{\delta-1}\right]+\frac{1}{2} \frac{w^{2}}{c e^{2}}$. Its first derivative with respect to profit sharing is $\pi_{\tau}=\frac{1}{\delta-1}\left[(1-\delta) w^{-\delta} e^{\delta-1} w_{\tau}+(\delta-1) w^{1-\delta} e^{\delta-2} e_{\tau}\right]+\frac{w c e^{2} w_{\tau}-w^{2} c e e_{\tau}}{\left(c e^{2}\right)^{2}}$ and by using $e_{\tau}=\frac{\gamma e}{\tau}$ we can rewrite it as: $\pi_{\tau}=\frac{w L}{\tau}\left(\gamma-\frac{w_{\tau} \tau}{w}\right)$. Using this term to solving the first-order condition $-\pi+(1-\tau) \pi_{\tau}=0$ yields the optimal committed profit sharing

$$
\tau^{c}=\frac{(\delta-1)\left(\gamma-\frac{w_{\tau} \tau}{w}\right)}{\left[1+(\delta-1)\left(\gamma-\frac{w_{\tau} \tau}{w}\right)+\frac{(1+\delta)}{2} \frac{M}{e L}\right]}
$$

and without outsourcing we have

$$
\left.\tau^{c}\right|_{M=0}=\bar{\tau}^{c}=\frac{(\delta-1)\left(\gamma-\frac{\overline{w_{\tau} \tau}}{\bar{w}}\right)}{\left[1+(\delta-1)\left(\gamma-\frac{\overline{w_{\tau} \tau}}{\bar{w}}\right)\right]} .
$$


To compare the profit share level, we have to take a look on the wage elasticity with respect to profit sharing in the case with and without outsourcing. Concerning the relationship between (19) and (20) we try to answer the inequality of committed profit sharing in the presence and absence of outsourcing, i.e. $\tau^{c}>\left.\tau^{c}\right|_{M=0}$. From this starting point we get the simplified expression (B2): $\underbrace{-\gamma \cdot \frac{1+\delta}{2} \cdot \frac{M}{e L}}_{-}-\frac{w_{\tau} \tau}{w}>-\frac{\overline{w_{\tau} \tau}}{\bar{w}} \underbrace{\left[1+\frac{1+\delta}{2} \cdot \frac{M}{e L}\right]}_{+}$(for details see Appendix B). Since the sign of the wage elasticity with respect to profit sharing is the decisive factor but we cannot identify the influence of profit sharing on wages (see (14) and (15)), we have to make some assumptions about the wage elasticity with respect to profit sharing. In terms of this issue we can distinguish the following four cases:

Case I: $\frac{w_{\tau} \tau}{w}>0$ and $\frac{\overline{w_{\tau} \tau}}{\bar{w}}<0$.

We can conclude that in this case the RHS of (B2) is positive and the LHS is negative. Since the given relation in our starting point is $\tau^{c}>\left.\tau^{c}\right|_{M=0}$ we see that this is not fulfilled. In this case we have a decreasing profit sharing if a firm engages in outsourcing activities.

Case II: $\frac{w_{\tau} \tau}{w}<0$ and $\frac{\overline{w_{\tau} \tau}}{\bar{w}}<0$.

In this case the RHS of (B2) is positive but the sign of the LHS is a priori ambiguous. Therefore, we cannot conclude in this case if profit sharing in the presence of outsourcing bigger or smaller than in the case without outsourcing.

Case III: $\frac{w_{\tau} \tau}{w}>0$ and $\frac{\overline{w_{\tau} \tau}}{\bar{w}}>0$.

In this case both sides of (B2) are negative but we cannot conclude if profit sharing in the presence of outsourcing is bigger or smaller than in the case without outsourcing.

Case IV: $\frac{w_{\tau} \tau}{w}<0$ and $\frac{\overline{w_{\tau} \tau}}{\bar{w}}>0$

In this case the RHS of (B2) is negative, but the sign of the LHS is a priori 
ambiguous. Therefore we cannot conclude if profit sharing in the presence of outsourcing is bigger or smaller than in the case without outsourcing.

We can summarize our findings to

Proposition 3: In the presence of flexible outsourcing, optimal committed profit sharing is smaller than in the absence of outsourcing if in absence of outsourcing profit sharing has a complementary character but in the presence of outsourcing a supplementary character.

For the special case of a zero effort elasticity but positive outsourcing, we can simplify the wage elasticity with respect to profit sharing to $\left.\frac{w_{\tau} \tau}{w}\right|_{\gamma=0} ^{M>0}=-\frac{\tau}{\hat{\eta}-(1-\tau)\left[1-\frac{\hat{\eta}_{w} w}{\hat{\eta}}\right]}$, with $\hat{\eta}=\delta+(1+\delta) \frac{M}{L}$. Solving for the optimal committed profit share we found

$$
\left.\tau^{c}\right|_{\gamma=0} ^{M>0}=1-\frac{\hat{\eta}\left(1+\frac{1+\delta}{2} \frac{M}{L}\right)}{\left(1+\frac{1+\delta}{2} \frac{M}{L}\right)\left(1-\frac{\hat{\eta}_{w} w}{\hat{\eta}}\right)-(1-\delta)}<0
$$

because $1-\frac{\hat{\eta}_{w} w}{\hat{\eta}}=-\hat{\eta}\left(1-\frac{\delta}{\hat{\eta}}\right)+\frac{\delta}{\hat{\eta}}<0$. This means that in the presence of outsourcing and zero effort elasticity, $\gamma=0$, the firm will desist from profit sharing. This is reasonable since in a case of zero effort elasticity the worker will only provide the minimum effort level of 1 . The provision of the minimum effort level is the dominate strategy for a worker, because he/she has no influence on the firm's profit. Since the decision about effort provision is unchanged also if the firm will set same incentives with introducing profit sharing, the firm will only distributed a part of her profit to the workers without effects on effort or profit. So it is beneficial for the firm to avoiding profit sharing. The same holds if the firm doesn't engage in outsourcing, i.e. $\left.\tau^{c}\right|_{\gamma=M=0}=\left.\tau^{c}\right|_{\gamma=0} ^{M>0}=0$ from (21). 


\section{Wage Formation by Monopoly Labour Union with Flexible Outsourcing and Flexible Profit Sharing}

We now use the timing structure (II) to analyze the wage formation by the monopoly labour union before flexible profit sharing by the representative firm, which means that the firm will decide for profit sharing after the wage level.

\subsection{Flexible Profit Sharing}

First we study the case when profit sharing is decided to maximize profit by taking the base wage as given and anticipating the outsourcing and labour demand decision and effort so that

$$
\begin{gathered}
\underset{\tau}{\operatorname{Max}} \bar{\pi}=(1-\tau)\left[\frac{\delta}{\delta-1}(e L+M)^{\frac{\delta-1}{\delta}}-w L-\frac{1}{2} c M^{2}\right] \text { s.t. } \\
L=w^{-\delta} e^{\delta-1}-\frac{M}{e}=w^{-\delta} e^{\delta-1}-\frac{w}{c e^{2}} \text { and } e=(\tau w)^{\gamma}
\end{gathered}
$$

The first-order condition is similar as in the case of committed profit sharing, i.e. $-\pi+(1-\tau) \pi_{\tau}=0$, where the indirect profit is $\pi=\frac{1}{\delta-1}\left[w^{1-\delta} e^{\delta-1}\right]+\frac{1}{2} \frac{w^{2}}{c e^{2}}$. In comparison with committed outsourcing case the partial derivative of the profit in terms of profit sharing is different because in this case the wage is given, i.e. $\pi_{\tau}=w^{1-\delta} e^{\delta-2} e_{\tau}-\frac{w^{2}}{c e^{3}} e_{\tau}=\frac{\gamma}{\tau}\left[w^{1-\delta} e^{\delta-1}-\frac{w M}{e}\right]=\frac{\gamma}{\tau} w L$, so that the first-order condition can be written as $\frac{1}{\delta-1}\left(w L+\frac{w M}{e}\right)+\frac{1}{2} \frac{w^{2}}{c e^{2}}=\frac{\gamma}{\tau}(1-\tau) w L$. This can be solved for the optimal flexible profit sharing in the presence of flexible outsourcing as

$$
\tau^{f}=\frac{(\delta-1) \gamma}{\left[1+(\delta-1) \gamma+\frac{(1+\delta)}{2} \frac{M}{e L}\right]} .
$$


This is also an implicit form, because both employee effort and labour demand also depend on profit sharing in a non-linear way. In the absence of outsourcing the optimal flexible profit share can be expressed as

$$
\left.\tau^{f}\right|_{M=0}=\bar{\tau}^{f}=\frac{(\delta-1) \gamma}{1+(\delta-1) \gamma} .
$$

Therefore under flexible profit sharing in the presence of outsourcing the optimal flexible profit share is smaller than in the absence of outsourcing, i.e. $\tau^{f}<\bar{\tau}^{f}$ because $\frac{(1+\delta)}{2} \frac{M}{e L}>0$.

After knowing the optimal value of the profit share, we can analyze the effects of changes in the outsourcing cost and the base wage (see Appendix C). Differentiating (23) first with respect to profit sharing and outsourcing cost gives

$$
\frac{d \tau^{f}}{d c}=\frac{\frac{(1+\delta) \tau^{2}}{2(\delta-1) \gamma} \frac{M}{e L c}\left(1+\frac{M}{e L}\right)}{1-\frac{(1+\delta) \tau}{2(\delta-1)}(1+\delta) \frac{M}{e L}\left(1+\frac{M}{e L}\right)}=?
$$

Since the nominator of (25) is positive, higher outsourcing cost will increase the optimal flexible profit share only if $1-\frac{(1+\delta) \tau}{2(\delta-1)}(1+\delta) \frac{M}{e L}\left(1+\frac{M}{e L}\right)>0$. If it is not the case, higher outsourcing cost will decrease the optimal flexible profit sharing. But in the absence of outsourcing there is no effect of outsourcing cost on flexible profit sharing, i.e. $\frac{d \bar{\tau}^{f}}{d c}=0$. Differentiating (23) with respect to profit sharing and wage gives

$$
\frac{d \tau^{f}}{d w}=\frac{-\frac{(1+\delta) \tau^{2}}{2(\delta-1)} \frac{(1-\gamma)}{\gamma}(1+\delta) \frac{M}{e L w}\left(1+\frac{M}{e L}\right)}{1-\frac{(1+\delta) \tau}{2(\delta-1)}(1+\delta) \frac{M}{e L}\left(1+\frac{M}{e L}\right)}=?
$$


Since the nominator is negative, higher wage will decrease the optimal flexible profit share only if $1-\frac{(1+\delta) \tau}{2(\delta-1)}(1+\delta) \frac{M}{e L}\left(1+\frac{M}{e L}\right)>0$. If it is not the case, higher wage formation will decrease the optimal flexible profit sharing. But also in the absence of outsourcing there is no effect of outsourcing cost on flexible profit sharing, i.e. $\left.\frac{d \bar{\tau}^{f}}{d c}\right|_{M=0}=0$. If the assumption is not fulfilled, then the opposite occurs and profit sharing will decrease with higher base wage. In the absence of outsourcing we have no effect of wage rate on flexible profit sharing, i.e. $\left.\frac{d \bar{\tau}^{f}}{d w}\right|_{M=0}=0$.

As in the committed case we can in flexible case show the impact of implementing profit sharing on outsourcing. Now the effect is described by $\frac{d M}{d \tau}=\frac{\partial M}{\partial e} \cdot \frac{\partial e}{\partial \tau}$ with $\frac{\partial e}{\partial \tau}=\frac{\gamma}{\tau} e$ and $\frac{\partial M}{\partial e}=-\frac{w}{e^{2} c}$, so that

$$
\frac{d M}{d \tau}=-\frac{\gamma}{\tau} \cdot M<0
$$

In opposite to implementing committed profit sharing here only the productivity effect will affect the outsourcing demand, since flexible profit sharing will not affect wage formation. As we mentioned earlier the productivity effect is intuitively. Since now workers participate on the firm profit, they have an incentive to increase the profit by higher effort. For given wage this will lead to higher labour demand so that some outsourcing activities will be avoided.

We can summarize these findings to

\section{Proposition 4:}

a) In the presence of flexible outsourcing optimal flexible profit sharing is smaller than in the absence of outsourcing. Moreover, lower outsourcing cost and higher wage will have ambiguous effects on optimal flexible profit sharing, but in the absence of outsourcing 
higher wage rate and outsourcing cost will have no effects on flexible profit sharing.

b) Implementing flexible profit sharing will increase worker's productivity and will substituting outsourcing by increasing domestic labour.

As in the case of committed profit sharing, we can also distinguish between the cases of a effort elasticity of zero, $\gamma=0$, and a positive elasticity with $0<\gamma<1$. It is easy to see from (23) and (24) that in the absence or presence of outsourcing zero effort

elasticity results in no flexible profit sharing, i.e. $\left.\tau^{f}\right|_{\gamma=0} ^{M>0}=\left.\tau^{f}\right|_{\gamma=M=0}=0$. The reason for this is, as mentioned in the committed case, that the worker will always provide the minimum level of effort since he has no influence on profit.

We can also compare equations (19) and (24) as well as (20) and (24) to give a statement about what for timing structure concerning profit sharing is preferred by the worker. In a general comparison, what includes the case of positive and no outsourcing, we found that the optimal committed profit share is higher as the optimal flexible profit share if committed profit sharing has a complementary character, $\frac{d w}{d \tau}<0$, i.e. $\tau^{c}>\tau^{f}$ and $\bar{\tau}^{c}>\bar{\tau}^{f}$ (see Appendix D). Of course in the case of zero effort elasticity the firm will always desists from profit sharing.

We can summarize these findings to

\section{Proposition 5:}

a) If in the committed case profit sharing has a complementary character on wages, then the committed profit share is higher as in the flexible case. The opposite holds if committed profit sharing has a supplementary character.

b) If committed profit sharing has no effect of wage formation, then the profit shares are in the committed and flexible case the same.

c) In the case of zero effort elasticity, there is no profit sharing as well as in the committed or flexible case and in the absence or presence of outsourcing. 


\subsection{Wage Formation under Flexible Profit Sharing}

We now analyze the wage formation by the monopoly labour union under flexible outsourcing by using the objective function (9). Maximizing in terms of the base wage subject to labour demand, effort determination, and profit sharing determination, gives

$$
V_{w}=L+L_{w}(w-b)+\tau \pi_{w}+\pi \tau_{w}-g(e) L_{w}-L g^{\prime}(e) e_{w}=0
$$

Additional to equation (10) under committed profit sharing there is the new term $\pi \tau_{w}$, which characterizes the effect of the wage formation on profit sharing. The solution of (28) is $w\left(\eta\left(1-\gamma \tau^{f}\right)+\tau^{f}-1-\tau^{f} \frac{\pi}{L}\right)=\eta b$, so that we have

$$
w=\left[\frac{\eta}{\eta\left(1-\gamma \tau^{f}\right)+\tau^{f}-1-\tau_{w}^{f} \frac{\pi}{L}}\right] b,
$$

which is also an implicit formulation for wage formation. In the case of flexible profit sharing, wage formation will affect profit sharing. For this term $\tau_{w}^{f}$ we found from equation (26) that $\frac{d \tau^{f}}{d w}=\tau_{w}^{f}=$ ?. Therefore the wage will have an ambiguous effect on optimal flexible profit sharing in the presence of flexible outsourcing, but no effect in the absence of outsourcing, i.e. $\bar{\tau}_{w}^{f}=0$. In the absence of outsourcing the wage formation is the following

$$
\left.w\right|_{M=0}=\bar{w}=\left[\frac{\bar{\eta}}{\bar{\eta}\left(1-\gamma \tau^{f}\right)+\tau^{f}-1}\right] b,
$$

which is an explicit specification, since $\bar{\eta}=(1-\gamma) \delta+\gamma$. Comparing equations (29) and (30) we know that in the absence of outsourcing the labour demand elasticity is smaller and the profit share is bigger than in the presence of outsourcing, i.e. 
$\bar{\eta}<\eta$ and $\tau^{f}<\bar{\tau}^{f}$. However there are opposed effects in the denominator, so we cannot give a statement whether the wage in the absence of outsourcing is bigger or smaller as in the presence of outsourcing, i.e. $w<\bar{w}$ or $w>\bar{w}$.

Indeed we can compare the wage in the committed and flexible case for some special assumptions.

Case I: No outsourcing $(M=0)$ and positive effort elasticity $(0<\gamma<1)$.

If there is no outsourcing, the labour demand elasticity is constant, $\bar{\eta}=(1-\gamma) \delta+\gamma$. And also we know from equation (24) that in the flexible case the wage does not influence the profit share, so we can rewrite the base wages as $\bar{w}^{c}=\left[\frac{\bar{\eta}}{\bar{\eta}\left(1-\gamma \tau^{c}\right)+\tau^{c}-1}\right] b$ and $\bar{w}^{f}=\left[\frac{\bar{\eta}}{\bar{\eta}\left(1-\gamma \tau^{f}\right)+\tau^{f}-1}\right] b$. A comparison of the wage levels show that the wage relation depends on the profit sharing level. If the optimal profit sharing in the flexible case smaller than in the committed case then the wage level in the flexible case is higher. As we mentioned in section 5.1 the relation of the profit share level depends on the wage reaction in the committed case (see also Appendix D). In the case of a complementary character of profit sharing in the committed case, i.e. $\frac{\partial \bar{w}^{c}}{\partial \tau^{c}}<0$, we found $\bar{\tau}^{c}>\bar{\tau}^{f}$. So a complementary profit income leads in the committed case to a higher profit share as in the flexible case, but this however results in lower base wage as in the flexible case, i.e. $\bar{w}^{c}<\bar{w}^{f}$. If the committed profit sharing has a supplementary character, i.e. $\frac{\partial \bar{w}^{c}}{\partial \tau^{c}}>0$, we know that $\bar{\tau}^{c}<\bar{\tau}^{f}$ which leads to $\bar{w}^{c}>\bar{w}^{f}$. The conclusion is that a higher profit share is financed by a smaller base wage.

Case II: No or positive outsourcing ( $M=0$ or $M>0$ ) and zero effort elasticity $(\gamma=0)$.

In this case we know, that the firm will abandon from profit sharing, so we can rewrite the wage in the flexible and committed case as $\left.w^{f}\right|_{\gamma=0}=\left.w^{c}\right|_{\gamma=0}=\frac{\eta}{\eta-1} b$ with $\left.\eta\right|_{\gamma=0}=\delta+(1+\delta) \frac{M}{L}$. This means that the income components are the same and the 
same also in the absence of outsourcing, so that the labour demand elasticity is $\left.\bar{\eta}\right|_{\gamma=0=M}=\delta<\left.\eta\right|_{\gamma=0}$. In this scenario the wage is smaller due to the wage moderation effect of outsourcing but is equal in the different timing structure concerning profit sharing.

We can sum up in the case of zero effort elasticity that the wages are the same, but higher in the absence of outsourcing.

\section{Proposition 6}

a) If the effort elasticity is zero, the wages are in both timing structure the same if the firm engage in outsourcing or not.

b) If there is no outsourcing but a positive effort elasticity higher profit sharing in the committed case will lead to a smaller wage in comparison to the flexible case and vice versa.

\section{Flexible Outsourcing, Profit Sharing and Equilibrium Unemployment}

Now we study the implications of outsourcing cost and profit sharing on equilibrium unemployment. Our focus is to characterize equilibrium unemployment as a function of institutional features of labour market, defined by the benefit-replacement ratio, the structure of compensation system and the outsourcing cost.

The wage formation by the monopoly labour union has the form

$$
w_{i}=A_{i} b
$$

in industry $i$, where the mark-up is defined by $A_{i}^{c}=\frac{\eta}{\eta\left(1-\gamma \tau^{c}\right)+\tau^{c}-1}$ in the case of 
committed profit sharing (equation (11)) and $A_{i}^{f}=\frac{\eta}{\eta\left(1-\gamma \tau^{f}\right)+\tau^{f}-1-\tau_{w}^{f} \frac{\pi}{L}}$ in the case of flexible profit sharing (equation (29)). We focus on the case with identical industries in terms of the wage mark-up, i.e. $A_{i}=A$. In a general equilibrium the outside option $b$ has to be specified as expected value of being not employed in one of the industries

$$
b=(1-u)\left(w+\tau \frac{\pi}{L}-g(e)\right)+u B
$$

where $u$ is the equilibrium unemployment rate and $B$ the unemployment benefit. According to (32) we assume that all identical industries adopt profit sharing as a part of the workers' compensation scheme so that an employed worker in one industry faces the probability $(1-u)$ of being employed in another industry, which makes use of a similar compensation scheme (for this kind of a standard justification, see e.g. Nickell and Layard (1999), pp. 3048-3050 and Layard et al. (2005), p. 100-101). The probability of being unemployed is characterized by $u$. In this case the individual receives the unemployment benefit $B$. Moreover, we assume a constant benefitreplacement ratio $q=B / w$ in the presence of unemployment, so that $0<q<1$. It is important to mention that in (31) and (32) both outsourcing cost and profit sharing affect the mark-up and the value of the outside option.

Combining (31) and (32) under assumption $q=B / w$ we can rewrite (31) as $w=A(1-u) w+A(1-u)\left(\tau \frac{\pi}{L}-g(e)\right)+A u q w$. From this the unemployment rate can be expressed in the case of committed profit sharing as $u^{c}=\frac{1-\frac{1}{A^{c}}-\frac{g(e)}{w}+\tau \frac{\pi}{w L}}{1-q-\frac{g(e)}{w}+\tau \frac{\pi}{w L}}$. By using $e=(\tau w)^{\gamma} \quad$ so that $\quad g(e) / w=\gamma \tau \quad$ and $\quad$ by using $\pi=\frac{1}{\delta-1}\left[w^{1-\delta} e^{\delta-1}\right]+\frac{1}{2} \frac{w^{2}}{c e^{2}}=\frac{1}{\delta-1}\left(w L+\frac{w M}{e}\right)+\frac{1}{2} \frac{w M}{e} \quad$ so $\quad$ that $\frac{\pi}{w L}=\frac{1}{\delta-1}\left[1+\frac{(1+\delta)}{2} \frac{M}{e L}\right]$ the unemployment rate can now be expressed as follows 


$$
u^{c}=\frac{1-\frac{1}{A^{c}}-\gamma \tau^{c}+\frac{\tau^{c}}{(\delta-1)}\left[1+\frac{(1+\delta)}{2} \frac{M}{e L}\right]}{1-q-\gamma \tau^{c}+\frac{\tau^{c}}{(\delta-1)}\left[1+\frac{(1+\delta)}{2} \frac{M}{e L}\right]} .
$$

where $\tau^{c}$ has been expressed in (19). In the absence of outsourcing we have

$$
\left.u^{c}\right|_{M=0}=\frac{1-\frac{1}{\left.A^{c}\right|_{M=0}}-\left.\gamma \tau^{c}\right|_{M=0}+\frac{\left.\tau^{c}\right|_{M=0}}{(\delta-1)}}{1-q-\left.\gamma \tau^{c}\right|_{M=0}+\frac{\left.\tau^{c}\right|_{M=0}}{(\delta-1)}}
$$

where $\left.\tau^{c}\right|_{M=0}$ has been expressed in (20).

Now we look at the implications on equilibrium unemployment when profit sharing is committed in terms of wage formation. Differentiating (33a) with respect to outsourcing cost by using $\quad N=1+\frac{(1+\delta)}{2} \frac{M}{e L}>0 \quad$ and $1-q-\gamma \tau+\frac{\tau}{(\delta-1)} N=T>0$ gives

$$
\frac{d u^{c}}{d c}=T^{-2}(\underbrace{\frac{d A^{c}}{d c}}_{?} \frac{\left.d A^{c}\right)^{2}}{T}+\underbrace{\left(\frac{\tau_{c} N+\tau N_{c}}{(\delta-1)}-\gamma \tau_{c}\right)}_{?} \underbrace{\left(\frac{1}{A^{c}}-q\right)}_{+})=?
$$

where $\frac{d A^{c}}{d c}=A_{c}^{c}+A_{w}^{c} \frac{d w}{d c}+A_{\tau}^{c} \frac{d \tau}{d c}=?, \tau_{c}=?$ and $N_{c}=-\frac{(1+\delta)}{2} \frac{M}{e L c}\left(1+\frac{M}{e L}\right)<0$.

For analyzing the impacts of outsourcing cost on equilibrium unemployment we have to distinguish two working channels, first the mark-up effect, and second the outside option effect. Since both are opposed or ambiguous the influence of outsourcing cost is a priori ambiguous. From our former analysis we know that higher outsourcing cost will increase the base wage due to a less elastic labour demand, but there is also an effect on the profit share, which we cannot identify. But the wage is increasing, since the advantage of outsourcing is decreasing with higher outsourcing cost. On the other hand higher outsourcing cost will reduce outsourcing demand and increase domestic 
labour demand, which implies a better employment chance and a better bargaining position due to an increasing value of the outside option. Now the trade union can be more aggressive, since the fear of dismissal employee are weaker, and set a higher wage. So we find that the outside option effect is harmful for the aim of low unemployment rates. Also the mark-up effect tends to be harmful for the wage income part but here the effect of the profit income can reverse this negative employment effect, but the mark-up effect is ambiguous. Therefore the effect of outsourcing cost on equilibrium unemployment is ambiguous.

Differentiating (33a) with respect to profit sharing gives

$$
\frac{d u^{c}}{d \tau}=T^{-2}(\underbrace{\frac{d A^{c}}{d \tau}}_{?} \frac{\left(A^{c}\right)^{2}}{+}+\underbrace{\left(\frac{\tau N_{\tau}+N}{(\delta-1)}-\gamma\right)}_{?} \underbrace{\left(\frac{1}{A^{c}}-q\right)}_{+})=?
$$

where $\frac{d A^{c}}{d \tau}=A_{\tau}^{c}+A_{w}^{c} \frac{d w}{d \tau}=$ ?, and $N_{\tau}=-\frac{(1+\delta)}{2} \frac{M}{e L \tau} \gamma(1+\delta)\left(1+\frac{M}{e L}\right)<0$. The impact of profit sharing on equilibrium unemployment is also a priori ambiguous for the following reasons. Higher profit sharing will have an ambiguous effect on the markup due to the direct effect via the opposed productivity and substitution channel and due to the wage increasing indirect channel via a less elastic wage elasticity. So the wage effect, which is described by the first term in brackets of (35a), is ambiguous. On the other side there is an outside option effect, which is characterized by the second term. Higher profit sharing leads to higher effort and increases the labour demand. The outsourcing demand is decreasing, since a part of the former outsourcing will be substituted by domestic effective labour, what is expressed in $N_{\tau}<0$. This leads for given wage to higher profits but it has to be weighted by the productivity. Since the employment chance is increased, this means that it would be easier to find a job in another industry. A better employment chance results in a higher outside option, so that the trade union will be more aggressive and set a higher wage. So the outside option effect has a positive effect on equilibrium unemployment.

In the absence of outsourcing the expression $N$ is simplified to $N=1$ with 
$N_{\tau}=0$ so that equation (35a) by using $1-q-\gamma \tau+\frac{\tau}{(\delta-1)}=\bar{T}$ can be re-expressed as

$$
\left.\frac{d u^{c}}{d \tau}\right|_{M=0}=\bar{T}^{-2}(\underbrace{\frac{d \bar{A}^{c}}{d \tau}}_{?} \overline{\left(\bar{A}^{c}\right)^{2}}+\underbrace{\left(\frac{1}{(\delta-1)}-\gamma\right)}_{?} \underbrace{\left(\frac{1}{\bar{A}^{c}}-q\right)}_{+})=? .
$$

This is also ambiguous in terms of equilibrium unemployment. But if $\gamma \geq \frac{1}{\delta-1}$ and $\left.\frac{d \bar{A}^{c}}{d \tau}\right|_{M=0}<0$, then higher profit sharing will decrease equilibrium unemployment.

In the case of flexible profit sharing equilibrium unemployment rate is $u^{f}=\frac{1-\frac{1}{A^{f}}-\frac{g(e)}{w}+\tau \frac{\pi}{w L}}{1-q-\frac{g(e)}{w}+\tau \frac{\pi}{w L}}$ and by using $\frac{\pi}{w L}=\frac{1}{\delta-1}\left[1+\frac{(1+\delta)}{2} \frac{M}{e L}\right]$ it can be expressed in the case of flexible profit sharing and flexible outsourcing as follows

$$
u^{f}=\frac{1-\frac{1}{A^{f}}-\gamma \tau^{f}+\frac{\tau^{f}}{(\delta-1)}\left[1+\frac{(1+\delta)}{2} \frac{M}{e L}\right]}{1-q-\gamma \tau^{f}+\frac{\tau^{f}}{(\delta-1)}\left[1+\frac{(1+\delta)}{2} \frac{M}{e L}\right]}
$$

where $\tau^{f}$ has been expressed in (23). In the absence of outsourcing we have

$$
\left.u^{f}\right|_{M=0}=\frac{1-\frac{1}{\left.A^{f}\right|_{M=0}}-\left.\gamma \tau^{f}\right|_{M=0}+\frac{\left.\tau^{f}\right|_{M=0}}{(\delta-1)}}{1-q-\left.\gamma \tau^{f}\right|_{M=0}+\frac{\left.\tau^{f}\right|_{M=0}}{(\delta-1)}}
$$

where $\left.\tau^{f}\right|_{M=0}$ has been expressed in (25).

The analysis of changes in the unemployment rate is simplified by the assumption of zero effort elasticity. We know that in this case there is no profit sharing neither in the 
committed nor flexible case. This means that the wages are identical but it does not mean that outsourcing demand is zero. So we can analyze the effect of changes in outsourcing cost on equilibrium unemployment for zero effort elasticity. In this scenario the unemployment rate can be written as $\left.u^{c}\right|_{\gamma=0}=\left.u^{f}\right|_{\gamma=0}=\frac{1-\frac{1}{\left.A\right|_{\gamma=0}}}{1-q}$ with $\left.A\right|_{\gamma=0}=\frac{\tilde{\eta}}{\tilde{\eta}-1}$ and $\tilde{\eta}=\delta+(1+\delta) \frac{M}{L}$ where the amount of outsourcing and labour demand are characterize as in the former analysis but with a constant effort of one and with an adjusted labour demand elasticity and wage. The influence of outsourcing cost on equilibrium unemployment can be written as

$$
\left.\frac{d u}{d c}\right|_{\gamma=0}=\frac{1}{\left.(1-q) A^{2}\right|_{\gamma=0}} \cdot \frac{\left.d A\right|_{\gamma=0}}{d c}>0
$$

where $\frac{\left.d A\right|_{\gamma=0}}{d c}=\underbrace{\frac{\partial A}{\partial \tilde{\eta}}}_{-} \cdot[\underbrace{\frac{\partial \tilde{\eta}}{\partial c}}_{-}+\underbrace{\frac{\partial \tilde{\eta}}{\partial w}}_{+} \cdot \underbrace{\frac{d w}{\partial c}}_{+}]>0$ (see Appendix E). This expression shows that only the mark-up is affected by the influence of outsourcing cost. Since the mark-up is increasing by higher cost of external procurement, increasing outsourcing cost lead to higher unemployment. This is reasonable, since higher outsourcing cost decrease the advantage of outsourcing but results in a more comfortable position for the trade union. So the union can be more aggressive and set a higher wage due to decreasing fear of substitution of the worker by outsourcing. The higher mark-up results in a decreasing labour demand which implies a negative employment effect.

We can summarize these findings to

\section{Proposition 7}

a) If there is profit sharing as a part of outside option in other industries both outsourcing cost and profit sharing will have ambiguous effects on equilibrium unemployment under committed and flexible profit sharing. In the absence of outsourcing the results are qualitatively similar. 
b) If the effort elasticity is zero, higher outsourcing cost will have an enhancing effect on unemployment.

\section{Conclusions}

We have analyzed the following questions associated with flexible outsourcing and with both committed and flexible profit sharing under imperfect domestic labour markets. How does flexible outsourcing - which we assume to be substitute for effective domestic labour - influence both wage formation and profit sharing? How does profit sharing influence flexible outsourcing? We have also studied the relationship between outsourcing, profit sharing and equilibrium unemployment.

We have shown that in both profit sharing scenarios lower outsourcing cost lowers the wage. In the presence of flexile outsourcing profit sharing is a supplementary or compensating part of income. If there is no outsourcing, profit sharing has also an ambiguous character. In the presence of flexible outsourcing optimal flexible profit sharing is positive but smaller than in the absence of outsourcing. Moreover, lower outsourcing cost and higher wage will have ambiguous effect on optimal flexible profit sharing.

In the case of zero effort elasticity there is of course no committed or flexible profit sharing in the absence or presence of outsourcing. In these cases the wages as the same both in the presence and absence of outsourcing. Under positive effort elasticity without outsourcing higher profit sharing will lead to a smaller wage compared to the flexible case and vice versa.

In terms of equilibrium unemployment the effects of outsourcing cost and profit sharing are ambiguous both in the committed and flexible profit sharing. In the absence of outsourcing profit sharing will also have an ambiguous unemployment effect. Moreover, if effort elasticity is zero, lower outsourcing cost will decrease unemployment.

There are new research topics associated with these issues. Very important issues are to study the implications of labour taxation and labour tax reforms on 
effort, labour demand, outsourcing, wage formation, profit sharing, equilibrium unemployment and social welfare. The question of how labour tax reform affects unionized firms, which engage in outsourcing is analyzed by Koskela and Schöb (2008), but they abstract from effort determination and the resulting productivity effects. It is also important to do numerical simulations associated with various results we have presented. Also one important research question would be to compare the effects of flexible outsourcing, analyzed in this paper, with strategic outsourcing. Which regime results in a higher degree of outsourcing?

\section{References:}

Akerlof, G.A. and J.L. Yellen (1986) (eds): Efficiency Wage Models of the Labor Market, Cambridge University Press, MA.

Amiti, M. and S.-J. Wei (2005): Fear of Service Outsourcing: Is It Justified?, Economic Policy, 20, 307-347.

BLACK, S.E. AND L.-M. LYNCH [2000], "What's Driving the New Economy: The Benefits of Workplace Innovation," NBER Working Paper 7479.

Booth, A.J. and J. Frank (1999): Earnings, Productivity, and Performed-Related Pay, Journal of Labor Economics, 17(3), 447-463.

Braun, S. and J. Scheffel (2007): A Note on the Effect of Outsourcing on Union Wages, SFB Discussion Paper 2007-034, Humbold Universität zu Berlin.

Cable, J. and N. Wilson (1990): Profit Sharing and Productivity: Some Further Evidence, the Economic Journal, 100, 550-555.

Cahuc, P. and B. Dormont (1997): Profit Sharing: Does It Increase Productivity and Employment? A Theoretical Model and Empirical Evidence on French Micro Data, Labour Economics, 4, 293-319.

Conyon, M. and R. Freeman (2001): Shared Modes of Compensation and Firm Performance: UK Evidence, NBER Working Paper No. 8448.

Dixit, A.K. and J.E. Stiglitz (1977): Monopolistic Competition and Optimal Product Diversity, American Economic Review, 67, 297-308.

Hasan, R., D. Mitra and R.W. Ramaswamy (2007): Trade Reforms, Labor Regulations, and Labor-Demand Elasticities: Empirical Evidence from India, the Review of Economics and Statistics, 89(3), 466-481. 
Koskela, E. (2008): The Effects of Labour Tax Progression under Nash-Bargaining and Flexible Outsourcing, IZA Discussion Paper No. 3501.

Koskela, E. and J. König (2008): Strategic Outsourcing, Profit Sharing, and Equilibrium Unemployment, IZA Discussion Paper No. 3413.

Koskela, E. and P. Poutvaara (2008): Flexible Outsourcing and the Impacts of Labour Taxation Progression in European Welfare States, HECER Discussion Paper No. 229.

Koskela, E. and R. Schöb (2008): Outsourcing of Unionized Firms and the Impact of Labour Market Policy Reforms, IZA Discussion Paper No. 3566.

Koskela, E. and R. Stenbacka (2006): Flexible and Committed Profit Sharing with Wage Bargaining: Implications for Equilibrium Unemployment, Journal of Economics, 87(2), 159-180.

Koskela, E. and R. Stenbacka (2007): Equilibrium Unemployment with Outsourcing under Labour Market Imperfections, IZA Discussion Paper No. 2628.

Kraft, K. and M. Ugarkovic (2005): Profit-Sharing: Supplement or Substitute?, Dortmund University, Germany.

Kruse, D.L. (1992): Profit Sharing and Productivity: Microeconomic Evidence from the United States, the Economic Journal, 102, 24-36.

Layard, R., S. Nickell and T. Jackman (2005): Unemployment: Macroeconomic Performance and the Labor Market, $2^{\text {nd }}$ edition, Oxford: Oxford University Press.

Lin, C.C., J.-J. Chang and C.-C. Lai (2002): Profit Sharing as a Worker Discipline Device, Economic Modelling, 19(5), 815-828.

Munch, J.R. and J.R. Skaksen (2005): Specialization, Outsourcing and Wages, IZA Discussion Paper No. 1907, forthcoming in: Review of World Economics.

Nickell, S. and R. Layard (1999): Labor Market Institutions and Economic Performance, in Ashenfelter, O. and D. Card (eds): Handbook of Labor Economics, Vol. 3C, North-Holland, 3029-3084.

Pendleton, A., E. Poutsma, J. van Ommeren and C. Brester (2001): Employee Share Ownership and Profit Sharing in the European Union, Office for Official Publications of the European Commission, Luxembourg.

Rishi, M. and S. C. Saxena (2004): Is Outsourcing Really as Bad as It Is Made Sound? A Re-assessment and Some Perspective, Working Paper, University of Pittsburg. 
Senses, M.Z. (2006): The Effects of Outsourcing on the Elasticity of Labor Demand, CES Discussion Paper, Washington D.C., March.

Sinn, H.-W. (2007): The Welfare State and the Forces of Globalization, CESifo Working Paper No. 1925.

Slaughter, M. (2001): International Trade and Labor-Demand Elasticities, Journal of International Economics, 54, 27-56.

Skaksen, J.R. (2004): International Outsourcing When Labor Markets Are Unionized, Canadian Journal of Economics, 37(1), 78-94.

Stefanova, B.M. (2006): The Political Economy of Outsourcing in the European Union and the East-European Enlargement, Business and Politics, 8, issue 2.

Wadhwani, S. and M. Wall (1990): The Effects of Profit Sharing on Employment, Wages, Stock Returns and Productivity: Evidence from U.K. Micro Data, the economic Journal, 100, 1-17.

Zhao, L. (20019: Unionization, Vertical Structure, and the Outsourcing of Multinationals, Journal of International Economics, 55, 187-202.

\section{Appendix A:}

Differentiating the wage formation (10) with respect to wage and profit sharing gives

$$
\begin{aligned}
& \left(1-\frac{[\eta(1-\gamma \tau)+\tau-1] \eta_{w}-\eta(1-\gamma \tau) \eta_{w}}{[\eta(1-\gamma \tau)+\tau-1]^{2}} b\right) d w= \\
& \frac{[\eta(1-\gamma \tau)+\tau-1] \eta_{\tau}-\eta(1-\gamma \tau) \eta_{\tau}-\eta(1-\eta \gamma)}{[\eta(1-\gamma \tau)+\tau-1]^{2}} b d \tau
\end{aligned}
$$

which can be expressed as

$$
\left(1-\frac{(\tau-1) \eta_{w}}{[\eta(1-\gamma \tau)+\tau-1]^{2}} b\right) d w=\frac{(\tau-1) \eta_{\tau}-\eta(1-\eta \gamma)}{[\eta(1-\gamma \tau)+\tau-1]^{2}} b d \tau
$$

Using $\quad b=\frac{w[\eta(1-\gamma \tau)+\tau-1]}{\eta} \quad$ (A2) can be expr
$\left(1-\frac{(\tau-1) \eta_{w} w / \eta}{[\eta(1-\gamma \tau)+\tau-1]}\right) d w=\frac{(\tau-1) \eta_{\tau} w / \eta-w(1-\eta \gamma)}{[\eta(1-\gamma \tau)+\tau-1]} d \tau$ so that we have

$$
\frac{d w}{d \tau}=\frac{(\tau-1) \eta_{\tau} w / \eta-w(1-\eta \gamma)}{\left(\eta(1-\gamma \tau)+(\tau-1)\left(1-\eta_{w} w / \eta\right)\right)}=?
$$

and 


$$
\left.\frac{d w}{d \tau}\right|_{M=0}=\frac{-w(1-\bar{\eta} \gamma)}{(\bar{\eta}(1-\gamma \tau)+\tau-1)}=?
$$

\section{Appendix B:}

From the equations (19) and (20) we can look on the relationship of $\tau^{c}$ and $\bar{\tau}^{c}$ by analyzing the inequation $\tau^{c}>\bar{\tau}^{c}$, which we can rewrite as

$$
\tau^{c}=\frac{(\delta-1)\left(\gamma-\frac{w_{\tau} \tau}{w}\right)}{\left[1+(\delta-1)\left(\gamma-\frac{w_{\tau} \tau}{w}\right)+\frac{(1+\delta)}{2} \frac{M}{e L}\right]}>\frac{(\delta-1)\left(\gamma-\frac{\overline{w_{\tau} \tau}}{\bar{w}}\right)}{\left[1+(\delta-1)\left(\gamma-\frac{\overline{w_{\tau} \tau}}{\bar{w}}\right)\right]}=\bar{\tau}^{c}
$$

which

leads

to

$$
(\delta-1)\left(\gamma-\frac{w_{\tau} \tau}{w}\right)\left[1+(\delta-1)\left(\gamma-\frac{\overline{w_{\tau} \tau}}{\bar{w}}\right)\right]>(\delta-1)\left(\gamma-\frac{\overline{w_{\tau} \tau}}{\bar{w}}\right)\left[1+(\delta-1)\left(\gamma-\frac{w_{\tau} \tau}{w}\right)+\frac{(1+\delta)}{2} \frac{M}{e L}\right]
$$

Simplifying this expression we get after some simple transformations

$$
-\gamma \cdot \frac{1+\delta}{2} \cdot \frac{M}{e L}-\frac{w_{\tau} \tau}{w}>-\frac{\overline{w_{\tau} \tau}}{\bar{w}}\left[1+\frac{1+\delta}{2} \cdot \frac{M}{e L}\right] .
$$

\section{Appendix C:}

Since equation (23) is an implicit expression we get for the derivative with respect to profit sharing and outsourcing cost

$$
\left(1+\frac{(\delta-1) \gamma \frac{(1+\delta)}{2} \frac{\partial}{\partial \tau}\left(\frac{M}{e L}\right)}{\left[1+(\delta-1) \gamma+\frac{(1+\delta)}{2} \frac{M}{e L}\right]^{2}}\right) d \tau^{f}=-\frac{(\delta-1) \gamma \frac{(1+\delta)}{2} \frac{\partial}{\partial c}\left(\frac{M}{e L}\right)}{\left[1+(\delta-1) \gamma+\frac{(1+\delta)}{2} \frac{M}{e L}\right]^{2}} d c
$$

Using the conversion $1+(\delta-1) \gamma+\frac{(1+\delta)}{2} \frac{M}{e L}=\frac{(\delta-1) \gamma}{\tau}$, we can simplifying (C1) to

$$
\left(1+\frac{(1+\delta)}{2(\delta-1) \gamma} \tau^{2} \frac{\partial}{\partial \tau}\left(\frac{M}{e L}\right)\right) d \tau^{f}=-\frac{(1+\delta)}{2(\delta-1) \gamma} \tau^{2} \frac{\partial}{\partial c}\left(\frac{M}{e L}\right) d c .
$$

The derivative of the ratio of outsourcing and effective labour with respect to profit sharing and outsourcing cost we can rewrite as

$$
\frac{\partial}{\partial \tau}\left(\frac{M}{e L}\right)=\frac{e L M_{\tau}-M\left(e L_{\tau}+L e_{\tau}\right)}{(e L)^{2}}=\frac{M}{e L \tau}\left[\frac{M_{\tau} \tau}{M}-\frac{L_{\tau} \tau}{L}-\frac{e_{\tau} \tau}{e}\right]
$$


$\frac{\partial}{\partial c}\left(\frac{M}{e L}\right)=\frac{e L M_{c}-M e L_{c}}{(e L)^{2}}=\frac{M}{e L c}\left[\frac{M_{c} c}{M}-\frac{L_{c} c}{L}\right]$

By using $\frac{M_{\tau} \tau}{M}=-\gamma, \frac{e_{\tau} \tau}{e}=\gamma, \frac{L_{\tau} \tau}{L}=(\delta-1) \gamma+\gamma(1+\delta) \frac{M}{e L}$ as well as $\frac{M_{c} c}{M}=-1$ and $\frac{L_{c} c}{L}=\frac{M}{e L}$ we can express $(\mathrm{C} 3 \mathrm{a})$ and $(\mathrm{C} 3 \mathrm{~b})$ as

$$
\begin{aligned}
& \frac{\partial}{\partial \tau}\left(\frac{M}{e L}\right)=-\frac{M}{e L \tau} \gamma(1+\delta)\left[1+\frac{M}{e L}\right]<0 \\
& \frac{\partial}{\partial c}\left(\frac{M}{e L}\right)=-\frac{M}{e L c}\left[1+\frac{M}{e L}\right]<0
\end{aligned}
$$

Substituting

$$
\text { (C4a) }
$$

and

(C4b)

into

give $\left(1-\frac{(1+\delta) \tau}{2(\delta-1)} \frac{M}{e L}(1+\delta)\left[1+\frac{M}{e L}\right]\right) d \tau^{f}=\frac{(1+\delta) \tau^{2}}{2(\delta-1) \gamma} \frac{M}{e L c}\left[1+\frac{M}{e L}\right] d c$, so that we have

$$
\frac{d \tau^{f}}{d c}=\frac{\frac{(1+\delta) \tau^{2}}{2(\delta-1) \gamma} \frac{M}{e L c}\left(1+\frac{M}{e L}\right)}{1-\frac{(1+\delta) \tau}{2(\delta-1)}(1+\delta) \frac{M}{e L}\left(1+\frac{M}{e L}\right)}=?
$$

Differentiating of (23) with respect to profit sharing and base wage we get

$$
\left(1+\frac{(\delta-1) \gamma \frac{(1+\delta)}{2} \frac{\partial}{\partial \tau}\left(\frac{M}{e L}\right)}{\left[1+(\delta-1) \gamma+\frac{(1+\delta)}{2} \frac{M}{e L}\right]^{2}}\right) d \tau^{f}=-\frac{(\delta-1) \gamma \frac{(1+\delta)}{2} \frac{\partial}{\partial w}\left(\frac{M}{e L}\right)}{\left[1+(\delta-1) \gamma+\frac{(1+\delta)}{2} \frac{M}{e L}\right]^{2}} d w,
$$

which we can simplify by using our former results to $\left(1+\frac{(1+\delta)}{2(\delta-1) \gamma} \tau^{2} \frac{\partial}{\partial \tau}\left(\frac{M}{e L}\right)\right) d \tau^{f}=\frac{(1+\delta)}{2(\delta-1) \gamma} \tau^{2} \frac{\partial}{\partial w}\left(\frac{M}{e L}\right) d w$, where

$\frac{\partial}{\partial w}\left(\frac{M}{e L}\right)=\frac{e L M_{w}-M\left(e L_{w}+L e_{w}\right)}{(e L)^{2}}=\frac{M}{e L w}\left[\frac{M_{w} w}{M}-\frac{e_{w} w}{e}-\frac{L_{w} w}{L}\right]$.

Inserting $\frac{M_{w} w}{M}=(1-\gamma), \frac{e_{w} w}{e}=\gamma$ and $\frac{L_{w} w}{L}=-(1-\gamma)\left[\delta+(1+\delta) \frac{M}{e L}\right]-\gamma$ as well as the above mentioned expressions, we get

$$
\frac{d \tau^{f}}{d w}=-\frac{\frac{(1+\delta) \tau^{2}}{2(\delta-1)} \frac{(1-\gamma)}{\gamma}(1+\delta) \frac{M}{e L w}\left(1+\frac{M}{e L}\right)}{1-\frac{(1+\delta) \tau}{2(\delta-1)}(1+\delta) \frac{M}{e L}\left(1+\frac{M}{e L}\right)}=?
$$




\section{Appendix D:}

From a comparison of equation (19) and (23) follows that $\tau^{c}>\tau^{f}$ holds if

$$
\tau^{c}=\frac{(\delta-1)\left(\gamma-\frac{w_{\tau} \tau}{w}\right)}{\left[1+(\delta-1)\left(\gamma-\frac{w_{\tau} \tau}{w}\right)+\frac{(1+\delta)}{2} \frac{M}{e L}\right]}>\frac{(\delta-1) \gamma}{\left[1+(\delta-1) \gamma+\frac{(1+\delta)}{2} \frac{M}{e L}\right]}=\tau^{f}
$$

This

$$
\text { expression }
$$

can

be

simplified

to

$$
\begin{gathered}
(\delta-1)\left(\gamma-\frac{w_{\tau} \tau}{w}\right)\left[1+\frac{(1+\delta)}{2} \frac{M}{e L}\right]>(\delta-1) \gamma\left[1+\frac{(1+\delta)}{2} \frac{M}{e L}\right], \text { so that we get } \\
-\frac{w_{\tau} \tau}{w}>0,
\end{gathered}
$$

what is fulfilled if $w_{\tau}<0$.

The same holds in the absence of outsourcing but here we have

$$
-\frac{\overline{w_{\tau} \tau}}{\bar{w}}>0
$$

what is fulfilled for $\bar{w}_{\tau}<0$.

\section{Appendix E:}

The mark-up in the case of zero effort elasticity is $\left.A\right|_{\gamma=0}=\frac{\tilde{\eta}}{\tilde{\eta}-1}$ with $\tilde{\eta}=\delta+(1+\delta) \frac{M}{L}$ and $M=\frac{w}{c}$ and $L=w^{-\delta}-M=w^{-\delta}-\frac{w}{c}$ since effort is constant at the level of one. From the expression $\left.\frac{d u^{f}}{d c}\right|_{\gamma=0}=\frac{1}{\left.(1-q) A^{2}\right|_{\gamma=0}} \cdot \frac{\left.d A\right|_{\gamma=0}}{d c}$ we see that in this case only the mark-up effect will drive the result. For the mark-up effect we find

$$
\frac{d A}{d c}=\frac{\partial A}{\partial \tilde{\eta}} \cdot\left[\frac{\partial \tilde{\eta}}{\partial c}+\frac{\partial \tilde{\eta}}{\partial w} \cdot \frac{d w}{d c}\right]
$$

where $\frac{\partial A}{\partial \tilde{\eta}}=-\frac{1}{(\tilde{\eta}-1)^{2}}<0, \frac{\partial \tilde{\eta}}{\partial c}=-\frac{1+\delta}{L} \cdot \frac{M}{c}\left(1+\frac{M}{L}\right)<0, \frac{\partial \tilde{\eta}}{\partial w}=\frac{(1+\delta) M}{w L}(1+\tilde{\eta})>0$.

and $\quad \frac{d w}{d c}=\frac{-\tilde{\eta}_{c} \cdot w}{\tilde{\eta}(\tilde{\eta}-1)+\tilde{\eta}_{w} \cdot w}>0$. Using these results into (E1) we get 
$\frac{d A}{d c}=\frac{\partial A}{\partial \tilde{\eta}} \cdot\left[-\frac{1+\delta}{L} \cdot \frac{M}{c}\left(1+\frac{M}{L}\right)+\frac{1+\delta}{L} \cdot \frac{M}{w}\left((1+\delta)\left(1+\frac{M}{L}\right)\right) \cdot \frac{d w}{d c}\right]$ what we can simplify to

$$
\frac{\left.d A\right|_{\gamma=0}}{d c}=\underbrace{\frac{\partial A}{\partial \tilde{\eta}}}_{-} \cdot \underbrace{\frac{(1+\delta) \cdot M}{c \cdot L} \cdot\left(1+\frac{M}{L}\right)}_{+}[\underbrace{\frac{(1+\delta) \cdot c}{w} \cdot \frac{d w}{d c}-1}_{-}],
$$

so we can concentrate on the third term. The sign of this term is negative if the relationship $\frac{d w}{d c} \frac{c}{w}<\frac{1}{1+\delta}$ holds. If we plug into this expression our former result for $\frac{d w}{d c}$ we get

$$
-(1+\delta) \cdot \tilde{\eta}_{c} \cdot c<\tilde{\eta}(\tilde{\eta}-1)+\tilde{\eta}_{w} \cdot w
$$

Using the earlier findings for $\tilde{\eta}_{w}$ and $\tilde{\eta}_{c}$ equation (E3) can be simplified to

$$
0<\tilde{\eta}(\tilde{\eta}-1) .
$$

Since this is true, we know that the third term in (E2) has a negative sign and therefore higher outsourcing cost raises the mark-up, i. e. $\frac{\left.d A\right|_{\gamma=0}}{d c}>0$. 